\title{
Medical empirical research on forest bathing (Shinrin-yoku): a systematic review
}

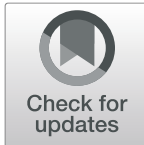

Ye Wen ${ }^{1,2}$, Qi Yan ${ }^{1}$, Yangliu Pan ${ }^{1}$, Xinren Gu ${ }^{1 *}$ and Yuanqiu Liu ${ }^{1 *}$

\begin{abstract}
Aims: This study focused on the newest evidence of the relationship between forest environmental exposure and human health and assessed the health efficacy of forest bathing on the human body as well as the methodological quality of a single study, aiming to provide scientific guidance for interdisciplinary integration of forestry and medicine.

Method: Through PubMed, Embase, and Cochrane Library, 210 papers from January 1, 2015, to April 1, 2019, were retrieved, and the final 28 papers meeting the inclusion criteria were included in the study.

Result: The methodological quality of papers included in the study was assessed quantitatively with the Downs and Black checklist. The methodological quality of papers using randomized controlled trials is significantly higher than that of papers using non-randomized controlled trials $(p<0.05)$. Papers included in the study were analyzed qualitatively. The results demonstrated that forest bathing activities might have the following merits: remarkably improving cardiovascular function, hemodynamic indexes, neuroendocrine indexes, metabolic indexes, immunity and inflammatory indexes, antioxidant indexes, and electrophysiological indexes; significantly enhancing people's emotional state, attitude, and feelings towards things, physical and psychological recovery, and adaptive behaviors; and obvious alleviation of anxiety and depression.
\end{abstract}

Conclusion: Forest bathing activities may significantly improve people's physical and psychological health. In the future, medical empirical studies of forest bathing should reinforce basic studies and interdisciplinary exchange to enhance the methodological quality of papers while decreasing the risk of bias, thereby raising the grade of paper evidence.

Keywords: Forest bathing (Shinrin-yoku), Systematic review, Methodology

\section{Introduction}

Subhealth is a third state between health and disease. The most common symptoms of subhealth are fatigue, poor sleep quality, forgetfulness, physical pain, and sore throat, and subhealth also increases the risk of infection and degrades the capacity of the immune system $[1,2]$. With the rapid development of the global economy and urbanization, increasing numbers of people have begun to show subhealth symptoms. In a survey conducted by the Ministry of Health, Labor and Welfare of Japan (32, 000 Japanese people over 12 years old), $54.2 \%$ of respondents considered their stress levels to be "very high" or "relatively high" [3]. It is estimated that one third of

\footnotetext{
* Correspondence: Jiujiuyl@163.com; Liuyq404@163.com

${ }^{1}$ College of Forestry, Jiangxi Agricultural University, 1101 ZhiMin Road,

Nanchang 330045, China

Full list of author information is available at the end of the article
}

American adults have nighttime sleep problems every week, and between 50 and 70 million people complain that nighttime sleep deprivation is mediated by daytime impairment $[4,5]$. A meta-analysis showed that between one third and one half of the population in the UK was affected by chronic pain, and the incidence of chronic pain in different body parts among adult residents was $35.0-51.3 \%$, and the incidence of chronic pain increased with age [6]. Under the background of the increasing number of people with subhealth around the world, forest bathing (Shinrin-yoku) therapy came about, which not only brings people with subhealth a healthy lifestyle advocated by modern medicine but also offers complementary therapies to the sick [7]. The term forest bathing was created in 1982 by the Ministry of Agriculture, Forestry and Fisheries of Japan [8]. It refers to a healing

(c) The Author(s). 2019 Open Access This article is distributed under the terms of the Creative Commons Attribution 4.0 International License (http://creativecommons.org/licenses/by/4.0/), which permits unrestricted use, distribution, and reproduction in any medium, provided you give appropriate credit to the original author(s) and the source, provide a link to the Creative Commons license, and indicate if changes were made. The Creative Commons Public Domain Dedication waiver (http://creativecommons.org/publicdomain/zero/1.0/) applies to the data made available in this article, unless otherwise stated. 
technique that restores the physical and psychological health of the human body through a "five senses experience" (vision, smell, hearing, touch, and taste) when the body is exposed to a forest environment. Forest bathing has positive effects on human physical and mental health $[9,10]$, especially in enhancing immunity, treating chronic diseases, regulating mood, and reducing anxiety and depression [11-14]. More benefits can be gained from exercising or meditating in a forest environment than in an urban environment $[15,16]$. In recent years, although medical empirical research on forest bathing has increased gradually, its healthcare mechanism for the human body has not been clearly defined due to a lack of research results, a low level of evidence, and a disciplinary barrier. Although forestry scholars and medical scholars have carried out relevant research on forest bathing therapy, there are still some limitations due to different research focuses. (1) The theoretical basis of research varies. Medical scholars mainly take evidence-based medicine as the theoretical basis for studying the physiological and psychological stress response of the human body during exposure to the forest environment to demonstrate the health-related effects of forest bathing. Forestry scholars mainly study the health mechanism of forest environmental factors and the relationship among them based on the theory of forestry. (2) The subject of research varies. The research subject of medical scholars is the human body, through studying changes in physiological and psychological indicators to directly verify the health-related effects of forest bathing. The research subject of forestry scholars is the forest environment, through the study of forest environmental factors of different variables to indirectly prove the health benefits of forest bathing. To solve this problem, this study uses the evidence-based medicine system evaluation method to qualitatively integrate the research results. The objectives are as follows: (1) focus on the latest evidence of the relationship between forest environment exposure and human health, (2) assess the methodological quality of individual studies, and (3) provide scientific theoretical guidance for the interdisciplinary integration of forestry and medicine.

\section{Methods}

\section{Selection criteria}

(1) Interventional study on the health effects of forest bathing. (2) Number of intervening measures is less than or equal to 3. (3) Trial was carried out in a forest environment. (4) The study period of the paper was from January 1, 2015, to April 1, 2019. (5) The paper is written in English. (6) Subjects are human.

\section{Paper search}

Through computer retrieval of PubMed, Embase, and Cochrane Library, we screened medical empirical research papers on forest bathing published in the last 5 years, and used a citation traceability method and Google academic search for papers that needed to be supplemented. In this study, the combination of subject words and free words was adopted, and the logical character "OR" was used to link each search term to obtain final search results. Search terms are shown in Table 4 in Appendix.

\section{Paper screening and data extraction}

Paper preliminary screening was conducted independently by one researcher through reviewing titles and abstracts, and data extraction was conducted independently by two researchers. After extraction, cross-checking was conducted, and disputes were resolved through discussion or referring to third-party opinions. Data extraction includes author name, publication year, study design, participant profile, ethical review, sample size, intervention measures, control measures, measurements, and outcomes.

\section{Quality assessment tool}

The methodological quality of the included studies was assessed using the Downs and Black checklist [17], which was used for quantitative evaluation of the quality of papers in randomized controlled trials (RCTs) and nonrandomized controlled trials (NRCTs). The evaluation included 27 items from 5 aspects of the paper: reporting, external validity, bias, confounding, and power. The evaluation was carried out by two researchers independently, and any disputes could be resolved through discussion or by referring to the opinions of a third party. The system evaluation report was prepared according to the Preferred Reporting Items for Systematic Reviews and MetaAnalyses [18] declaration standard.

\section{Results}

\section{Search results}

Initially, 210 papers were searched, and 17 duplicate papers and 133 irrelevant papers were removed based on title and abstract. Subsequently, we evaluated the full text and excluded 32 papers. Finally, 28 papers met the criteria for inclusion in the study. The screening process is shown in Fig. 1.

\section{General characteristics}

General characteristics of the included studies are shown in Table 1. A total of five countries or regions, including Japan, South Korea, Poland, China, and Taiwan, have conducted empirical studies on the health effects of forest bathing [19-46], among which 27 studies were conducted in Asian countries [19-34, 36-46] and 1 study [35] in a European country. Japanese scholars had the largest number of studies, publishing 13 papers [19, $20,22-25,28,31,38,40,42-44]$, accounting for $46 \%$ of the total number of included studies, followed by 


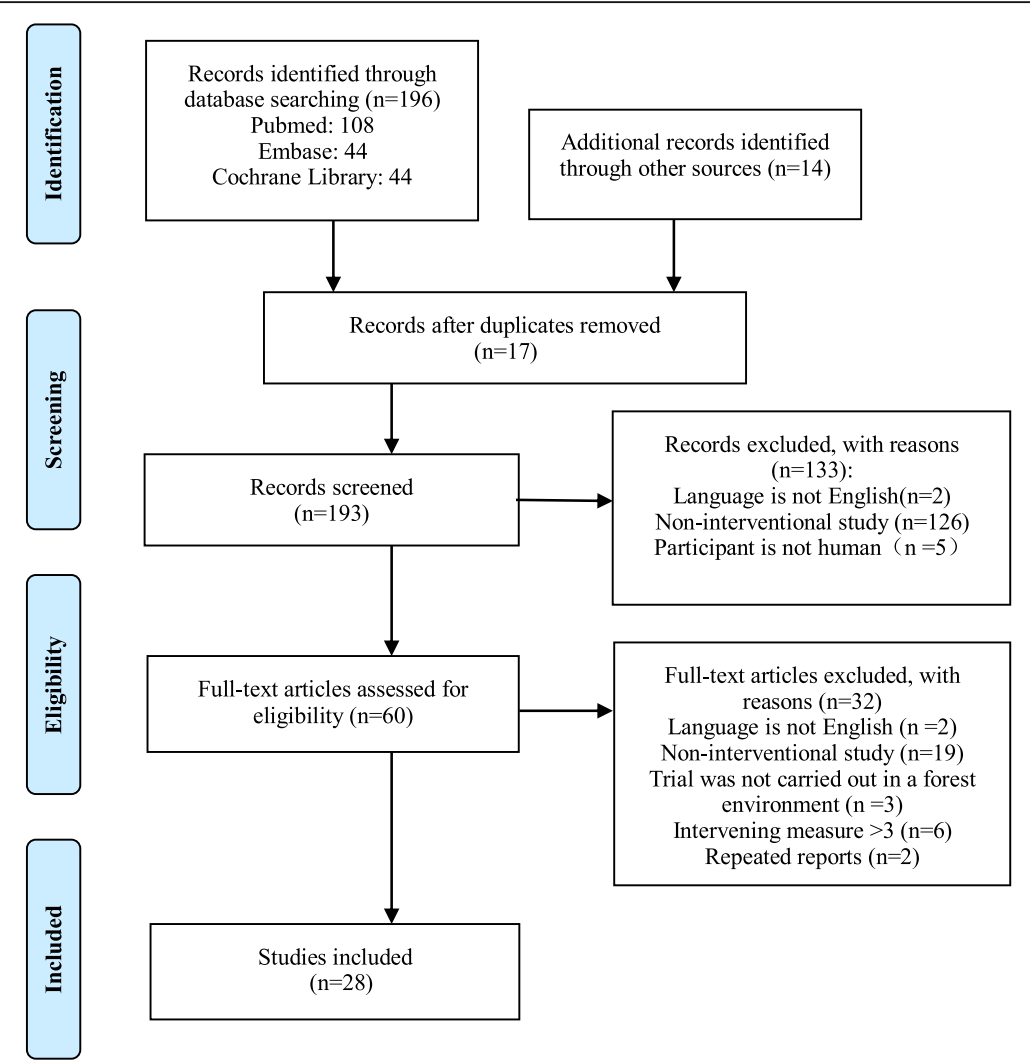

Fig. 1 Flow diagram of the screening process

Chinese, South Korean, Taiwanese, and Polish scholars, publishing 6 papers [27, 32, 37, 39, 45, 46], 5 papers [21, $26,29,30,34], 3$ papers [33, 36, 41], and 1 paper [35], respectively, accounting for $21 \%, 18 \%, 11 \%$, and $4 \%$ of the total number of included studies, respectively. Among them, there were 17 RCTs [20, 21, 24-27, $30-32,35,37-40,43,45,46]$, accounting for $61 \%$ of the total number of included studies, and 11 NRCTs $[19,22,23,28,29,33,34,36,41,42,44]$, accounting for $39 \%$ of the total number of included studies. The participants were dominated by healthy people, with a total of 17 studies [20, 24, 26, 29, 31, 33-38, 40, 42-46], accounting for $61 \%$ of the total number of studies included, and mostly young people aged 18-30. There were 11 studies $[19,21-23,25,27,28,30,32,39,41]$ on people with health problems, accounting for $39 \%$ of the total number of studies, most of which were middle-aged and elderly people over 45 years old. There were 13 studies $[19,21,24,29-31,33,34,37,38,40,43,45]$ with more than 50 samples, accounting for $46 \%$ of the total number of included studies, 8 studies [20, 22, 23, 25, 27, 36, 41, 44] with less than 20 samples and 7 studies [26, 28, 32, 35, 39, $42,46]$ with $20-50$ samples, accounting for $29 \%$ and $25 \%$ of the total number of included studies, respectively. There were 20 forest bathing studies $[19,20,22-26,28$, $31,33,35-38,40,42-46]$ that lasted for 1-3 days, accounting for $71 \%$ of the total number of included studies. There were 8 forest bathing studies $[21,27,29,30,32$, $34,39,41]$ that lasted for more than 3 days, accounting for $29 \%$ of the total number of included studies. Most scholars have taken ethical considerations into account when carrying out research. A total of 25 studies [19, 20, 22-44] have passed the ethical review, accounting for $89 \%$ of the total included studies. This was not mentioned in 3 studies $[21,45,46]$, accounting for $11 \%$ of the total number of included studies. There were 3 interdisciplinary studies [44-46], accounting for $11 \%$ of the total included studies.

\section{Intervention measures and control measures}

The detailed characteristics of the included research papers are shown in Tables 2 and 3. All studies take forest or urban environment exposure as the trial premise, and more than one or two intervention measures are adopted to carry out the trial, and some control measures are imposed. The interventions are mostly walking, meditation, yoga, Pilates, sightseeing, and crafts. The "five senses experience" and exercise are at the core. The control measures of each study are similar, mainly including the following: (1) control trial time and activity space; (2) prohibit or control tobacco, alcohol, and caffeine intake; (3) prohibit or allow use of drugs and 
Table 1 General characteristics of included studies $(n=28)$

\begin{tabular}{|c|c|c|}
\hline Characteristic & Categories & No. (\%) \\
\hline \multirow[t]{5}{*}{ Country or region } & China & $6(21)$ \\
\hline & Korea & $5(18)$ \\
\hline & Japan & $13(46)$ \\
\hline & Poland & $1(4)$ \\
\hline & Taiwan & $3(11)$ \\
\hline \multirow[t]{2}{*}{ Research design } & $\mathrm{RCT}$ & $17(61)$ \\
\hline & $\mathrm{NRCT}$ & $11(39)$ \\
\hline \multirow[t]{2}{*}{ Participant } & Healthy people & $17(61)$ \\
\hline & People with health problems & $11(39)$ \\
\hline \multirow[t]{5}{*}{ Average age (years) } & $18 \leq$ & $1(3.5)$ \\
\hline & $>18 \leq 30$ & $12(43)$ \\
\hline & $>30 \leq 45$ & $1(3.5)$ \\
\hline & $>45$ & $12(43)$ \\
\hline & Age unknown & $2(7)$ \\
\hline \multirow[t]{3}{*}{ Sample size } & $\leq 20$ & $8(29)$ \\
\hline & $>20 \leq 50$ & $7(25)$ \\
\hline & $>50$ & $13(46)$ \\
\hline \multirow[t]{2}{*}{ Time } & 3 days $\leq$ & $20(71)$ \\
\hline & $>3$ days & $8(29)$ \\
\hline \multirow[t]{2}{*}{ Ethical consideration } & Yes & $25(89)$ \\
\hline & No & $3(11)$ \\
\hline \multirow[t]{2}{*}{ Interdisciplinary research } & Yes & $3(11)$ \\
\hline & No & $25(89)$ \\
\hline
\end{tabular}

electronic products; (4) control of accommodation and diet; (5) consideration of female physiological period factors; and (6) increase buffer time (many hours or days) in a cross-over study to prevent carryover effect.

\section{Evaluative measures}

The evaluative measures for the healthcare effect of forest bathing are generally divided into self-reported measures and physiological measures according to different research purposes for choosing the appropriate evaluative measures, both of which can reflect the psychological and physiological stress response of the human body. Self-reported measurement combined with physiological indicators was the largest research method and used a total of 16 studies [19, 20, 22, 23, 25-30, 32-34, $36,37,43]$, accounting for $57 \%$ of the total included studies. There are 6 studies each that only use selfreported measurement $[21,35,40,44-46]$ or physiological indicator measurement $[24,31,38,39,41,42]$, each accounting for $21.5 \%$ of the total number of included studies. Self-reported measurement is widely used because it is simple to measure and easy to conduct quantitative analysis. Currently, internationally accepted self-reported measurement has been applied in the empirical research of forest bathing. Some scholars also use a homemade scale for research $[45,46]$. In physiological measures, due to the limitation of the trial environment, blood, urine, or saliva samples that require strict storage time and temperature are generally collected on the spot before and after the forest bathing, or at a place with good medical conditions according to the different testing items. Physiological indicators such as blood pressure, heart rate, pulse, and brain waves are generally measured by portable instruments.

\section{Physiological response \\ Cardiovascular function and hemodynamic indexes}

There were 8 studies $[19,22,28,29,33,36,37,39]$ involving blood pressure, and systolic blood pressure (SBP) and diastolic blood pressure were significantly reduced in 4 of these studies [19, 22, 33, 37], while only SBP was significantly decreased in 1 study [24], and only SBP was significantly increased in 1 study [15]. There were 4 studies $[23,28,33,36]$ in which pulse was significantly decreased. There were 3 studies $[20,25,43]$ involving heart rate, which was significantly decreased in 2 studies [25, 43]. There were 7 studies $[20,25,29,33,34$, 38,43 ] involving heart rate variability (HRV); the natural logarithmic value of the high frequency (lnHF) of HRV was significantly increased in 4 studies [20, 25, 38, 43], and the natural logarithmic value of the low frequency (lnLF)/lnHF of HRV was significantly decreased in 2 studies [38, 43]. There were 2 studies [32, 39] in which brain natriuretic peptide was significantly decreased. There was 1 study [32] in which Endothelin-1 was significantly decreased.

\section{Neuroendocrine indexes}

There were 3 studies $[23,27,31]$ in which cortisol was significantly decreased. There were 3 studies $[22,27,28]$ involving adrenaline, which was significantly decreased in 2 studies [22, 27]. There was 1 study [28] involving norepinephrine and dopamine, which were significantly decreased.

\section{Metabolism indexes}

There were 2 studies [28, 29] involving triglycerides, which were significantly decreased in 1 study [29]. There was 1 study [28] involving adiponectin, which was significantly increased.

\section{Immune and inflammatory indexes}

There were 2 studies [27, 41] involving nature killer (NK) cells, which were significantly decreased in 1 study [27]. There was 1 study [27] involving NKT-like cells, which were significantly decreased. There was 1 study [41] involving NK cell activity, which was significantly increased. There were 4 studies [26, 27, 32, 39] involving 


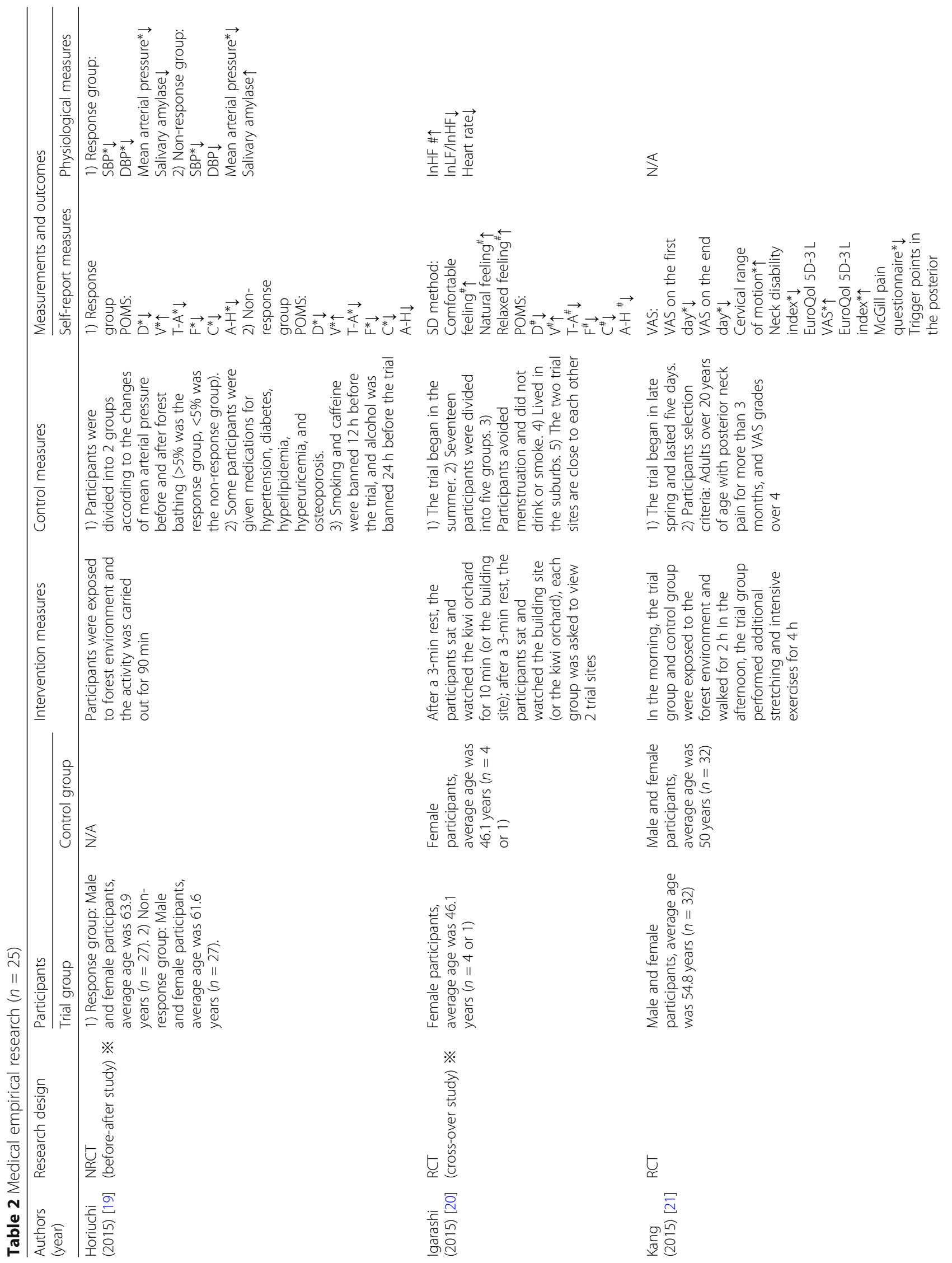




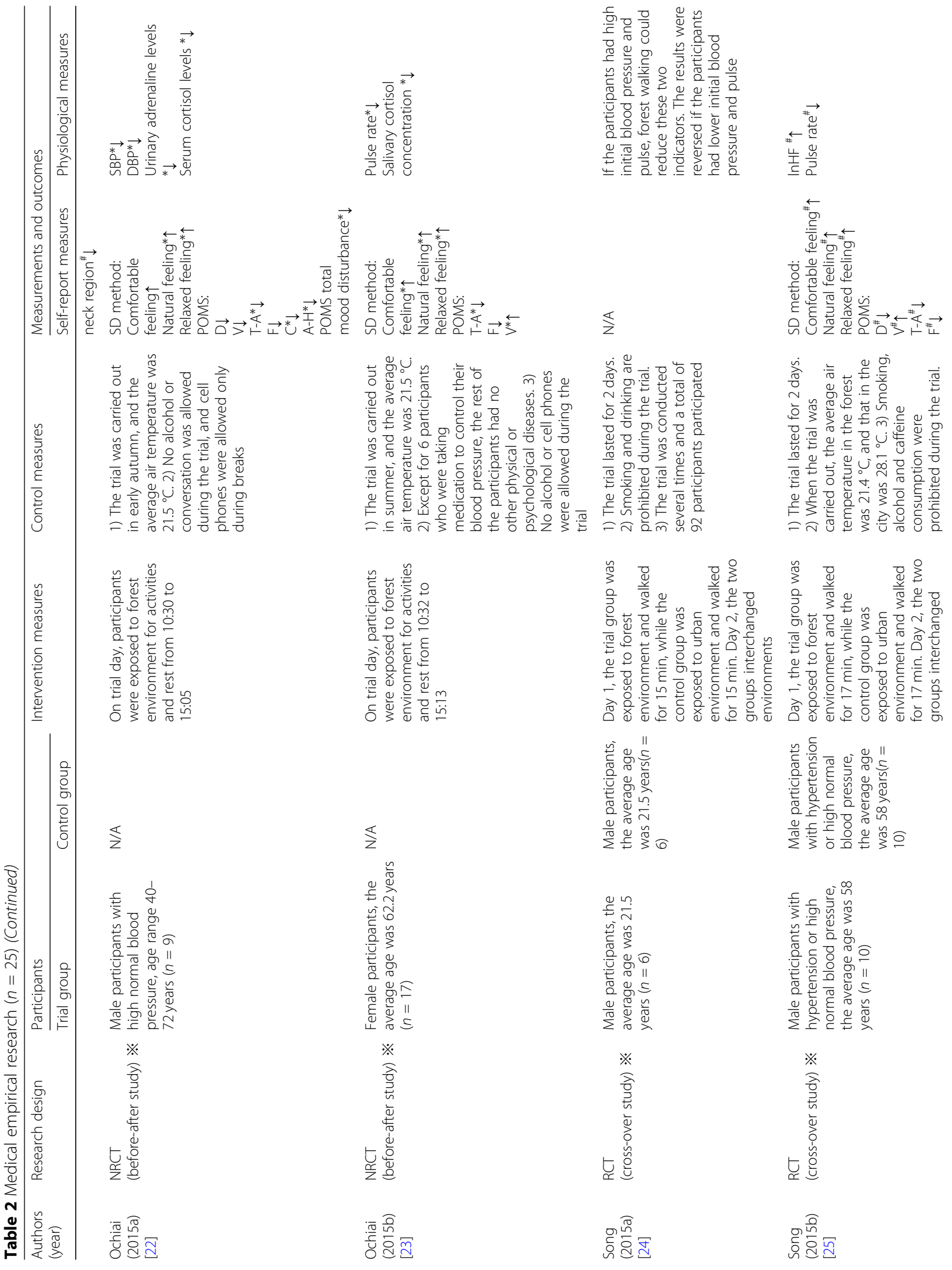




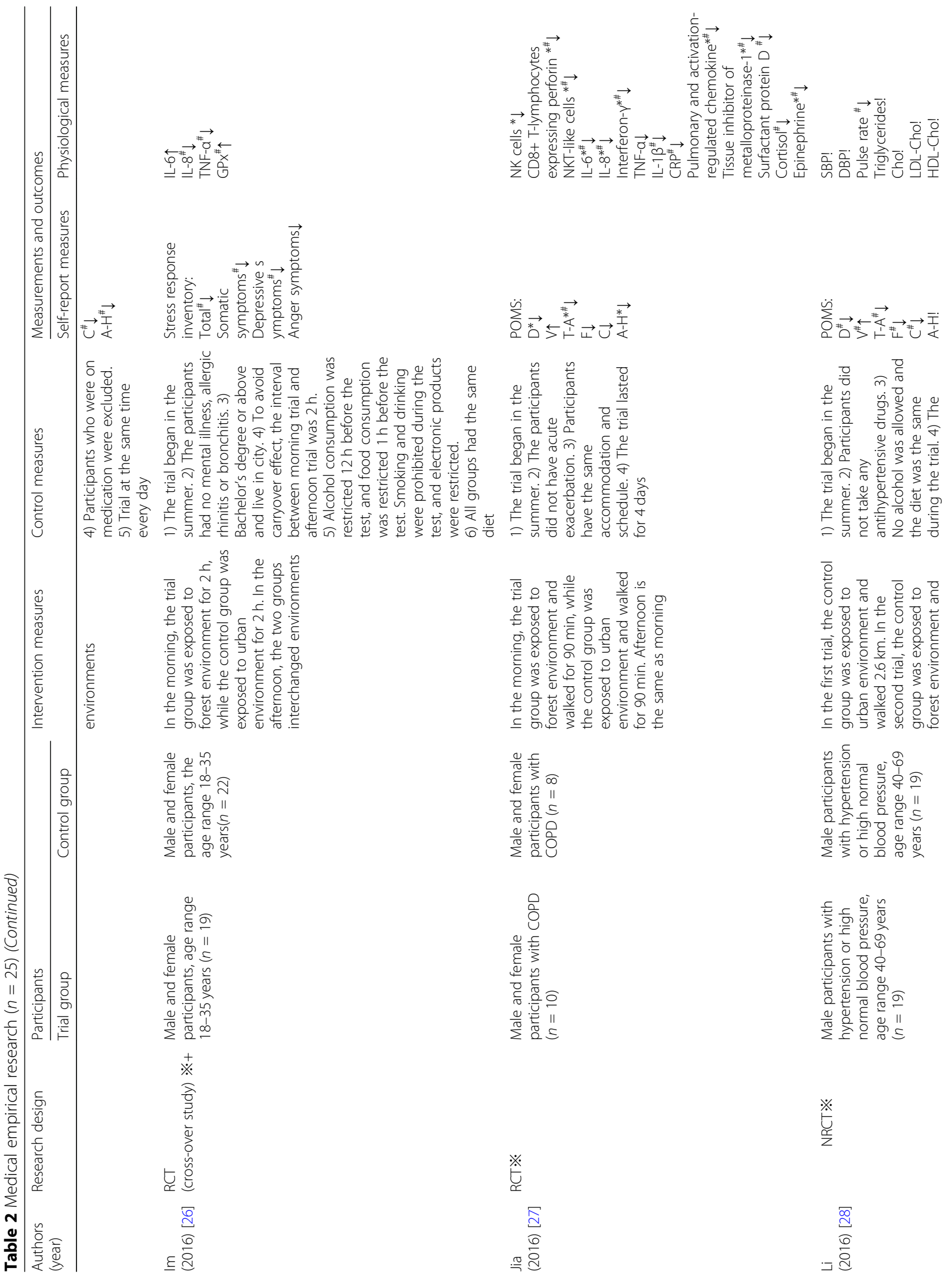




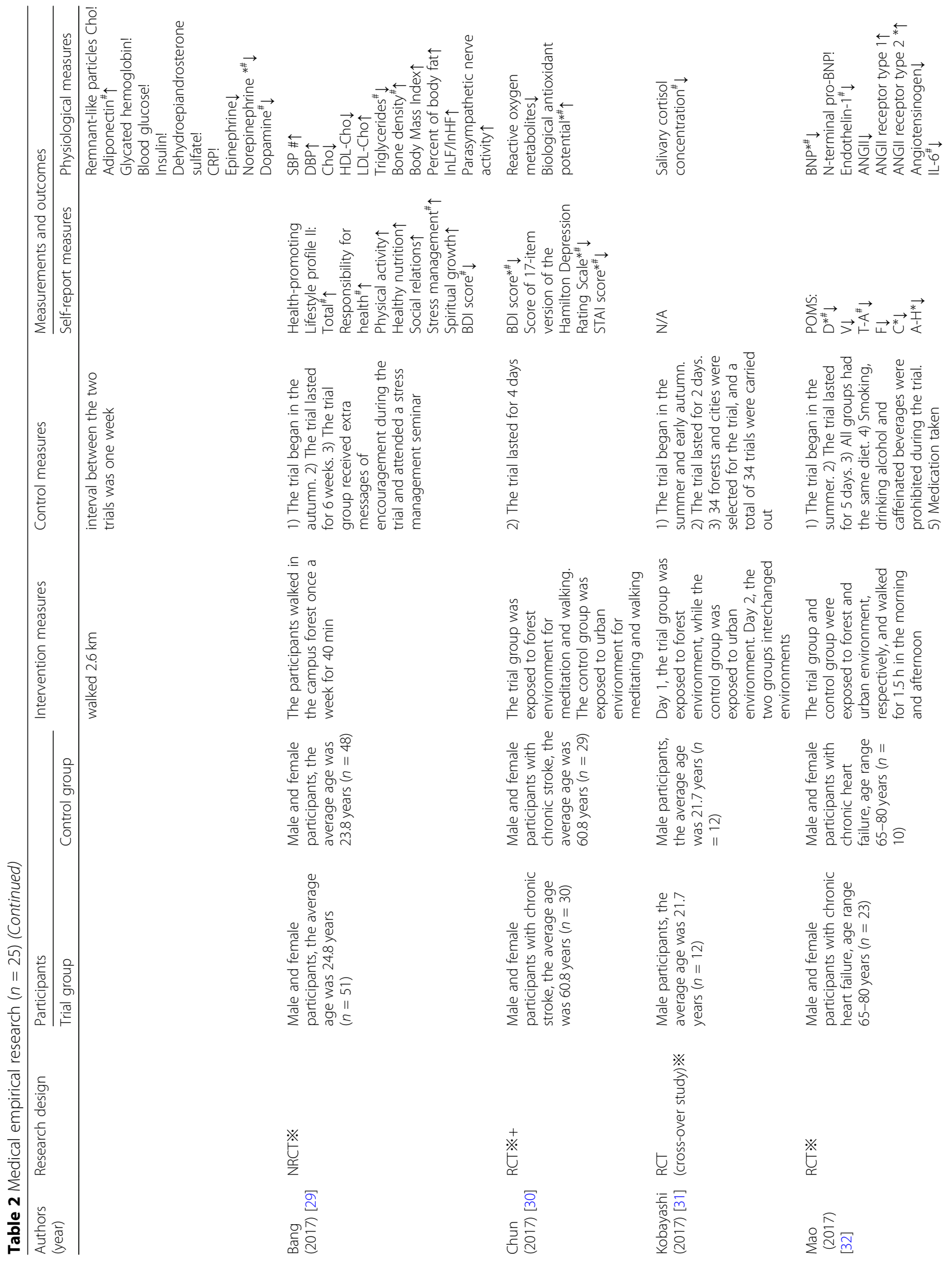




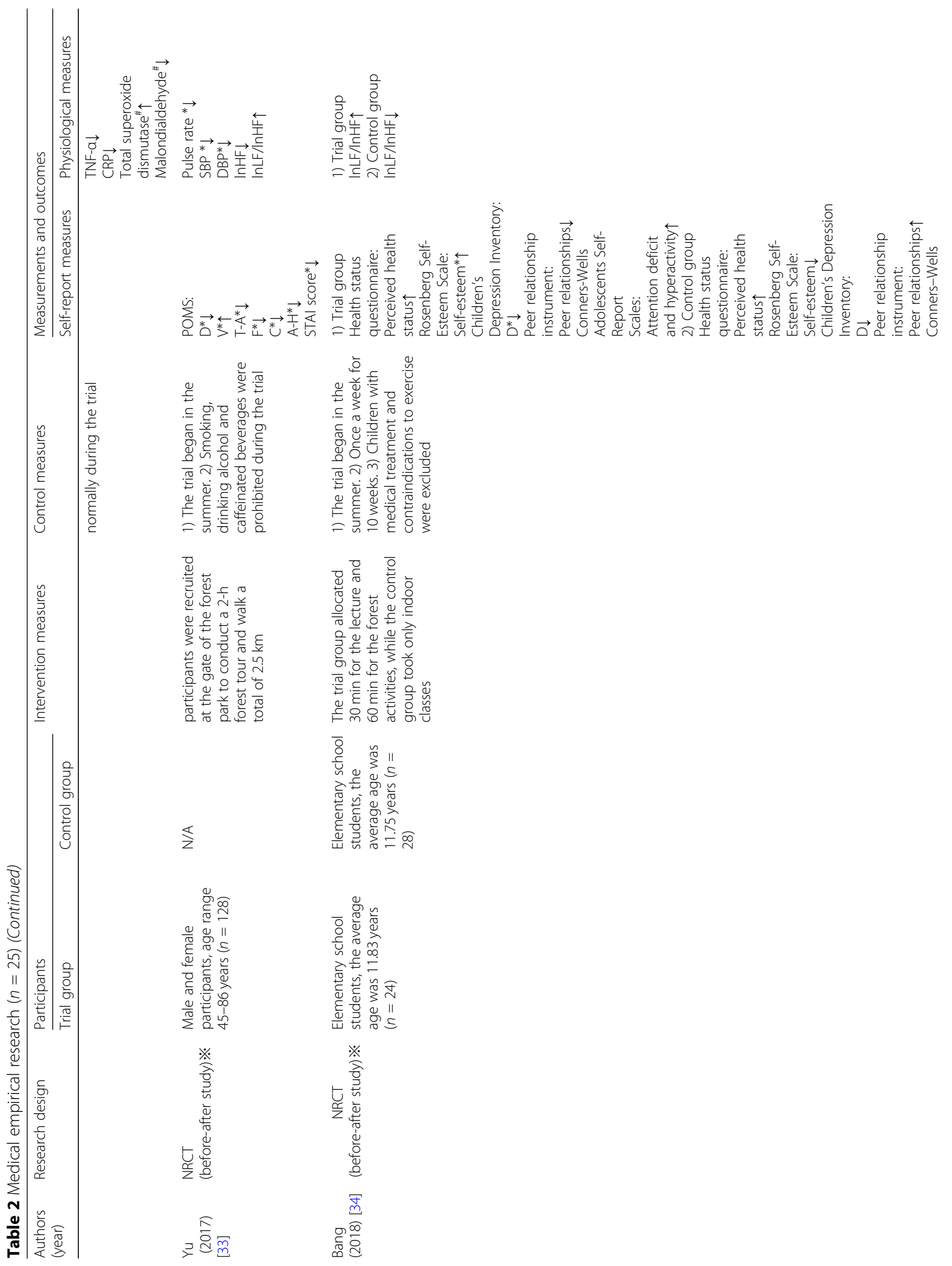




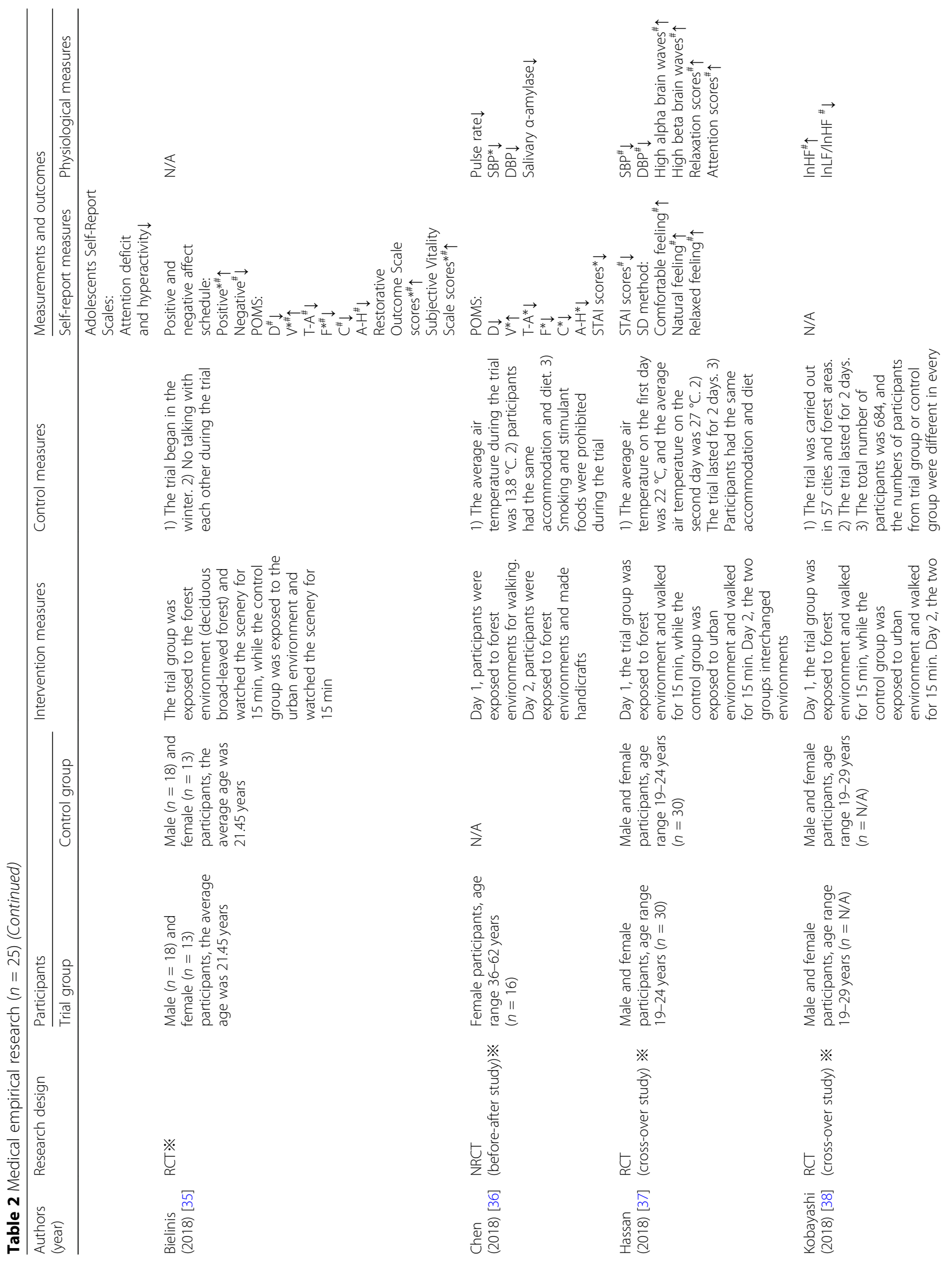




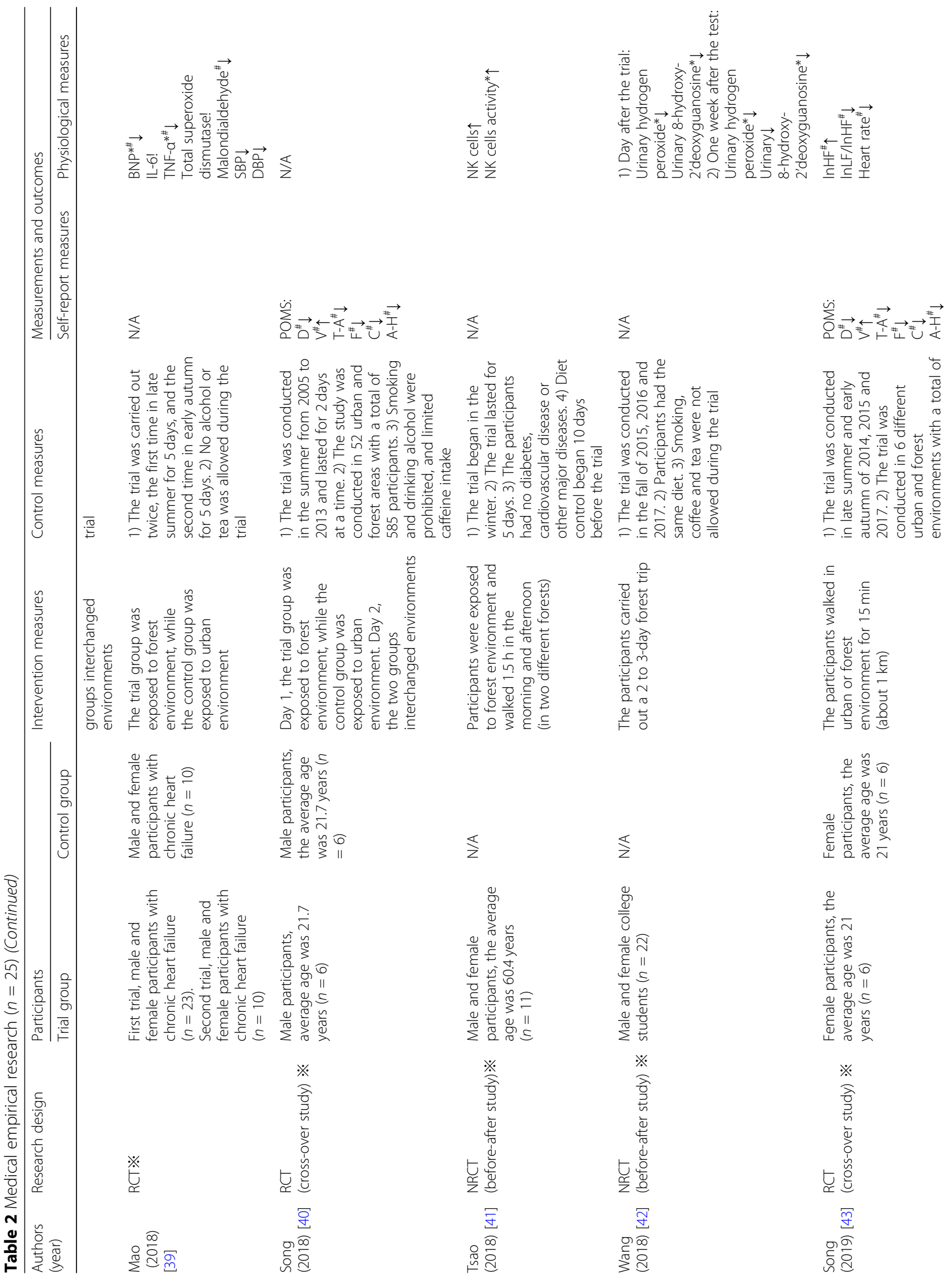




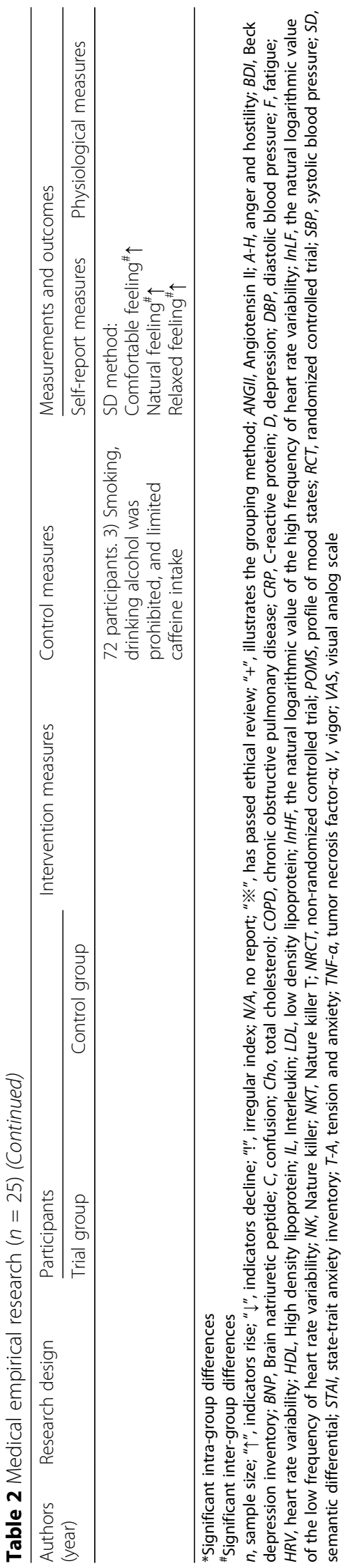




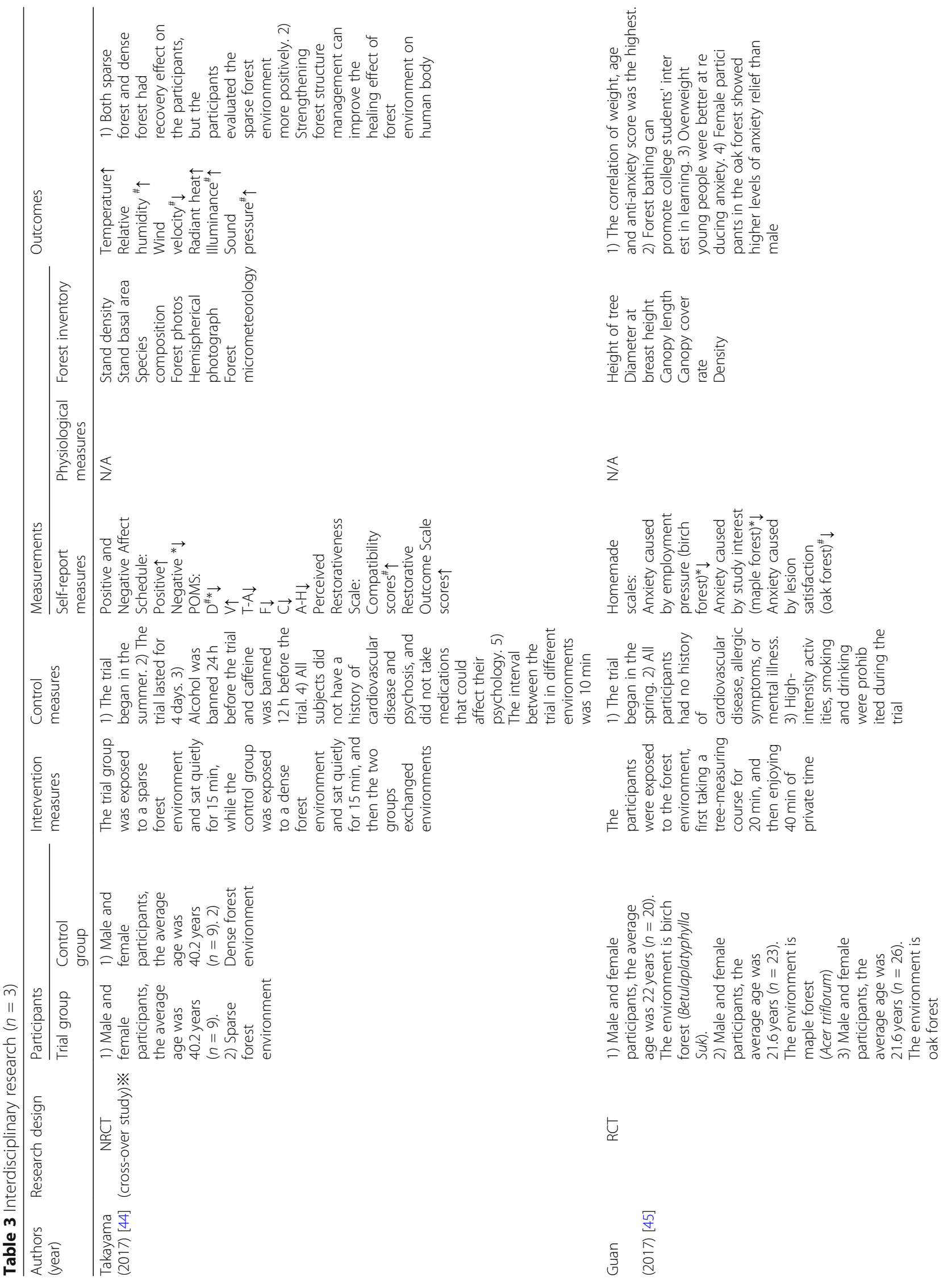




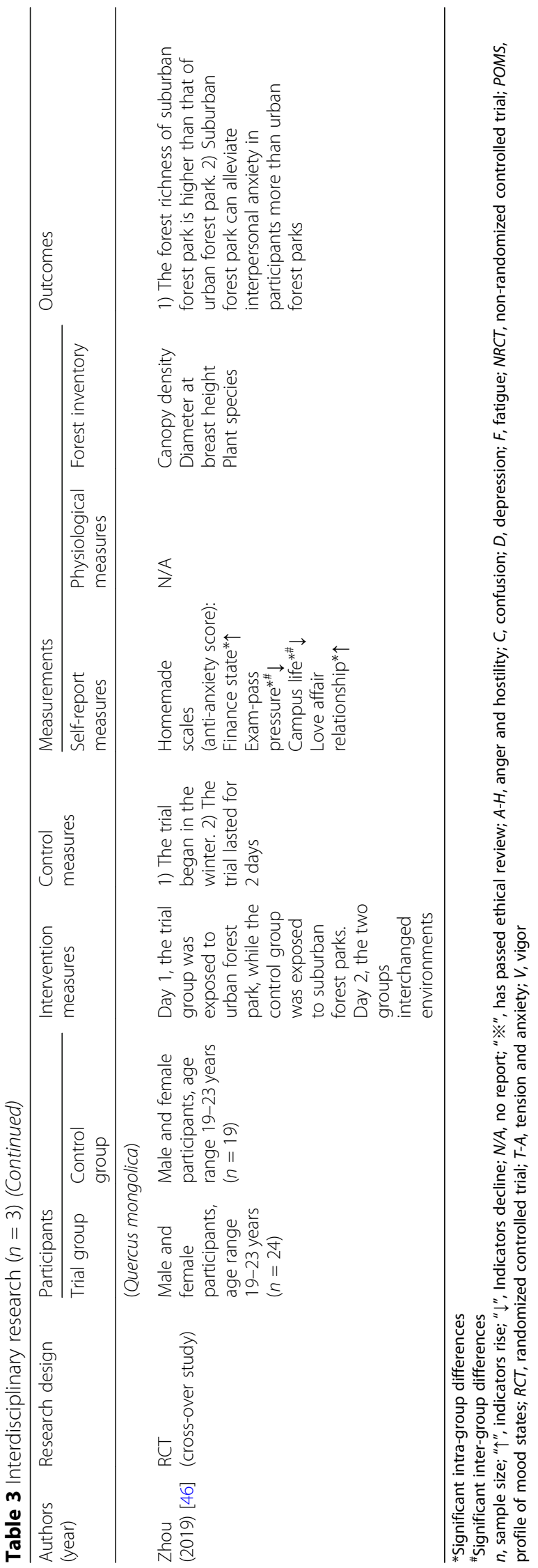


Interleukin (IL)-6, which was significantly decreased in 2 studies [27, 32]. There were 2 studies [26, 27] involving IL-8, which was significantly decreased. There were 3 studies [26, 32, 39] involving tumor necrosis factoralpha, which was significantly decreased in 2 studies [26, 39]. There were 3 studies [27, 28, 32] involving Creactive protein, which was significantly decreased in 1 study [27]. There was 1 study [27] involving IL-1 $\beta$, Interferon- $\gamma$, pulmonary and activation-regulated chemokine, tissue inhibitor of metalloproteinase- 1 and surfactant protein $\mathrm{D}$, which were all significantly decreased.

\section{Antioxidant indexes}

There was 1 study [26] involving glutathione peroxidase, which was significantly increased. There was 1 study [30] involving biological antioxidant potential, which was significantly increased. There was 1 study [42] involving 8-hydroxy-2'deoxyguanosine and hydrogen peroxide, which were significantly decreased. There were 2 studies [32, 39] involving total superoxide dismutase, which was significantly increased in 1 study [32]. There were 2 studies [32, 39] involving malondialdehyde, which was significantly decreased.

\section{Electrophysiological indexes}

There was 1 study [37] involving electroencephalogram, high alpha brain waves and high beta brain waves, which were significantly increased, and the degree of relaxation of the human body was significantly increased.

\section{Psychological outcomes \\ Emotional states}

There were 14 studies $[19,20,22,23,25,27,28,32,33$, $35,36,40,43,44]$ involving the emotional states of humans. Among them, "depression," "tension-anxiety," "fatigue," "confusion," and "anger-hostility" scores were significantly decreased in 11 studies [19, 20, 25, 27, 28, 32 , 33, 35, 40, 43, 44], 13 studies [19, 20, 22, 23, 25, 27, $28,32,33,35,36,40,43], 9$ studies [19, 20, 25, 28, 33, $35,36,40,43], 11$ studies [19, 20, 22, 25, 28, 32, 33, 35, $36,40,43]$, and 11 studies [19, 20, 22, 25, 27, 32, 33, 35, $36,40,43]$ respectively. There were 10 studies $[19,20$, $23,25,28,33,35,36,40,43]$ in which the "vigor" score was significantly increased. In addition, 2 studies [35, 44] showed that forest bathing significantly increased positive emotions and decreased negative emotions.

\section{Attitudes and feelings towards things}

There were 6 studies [20,22, 23, 25, 37, 43] involving people's attitudes and feelings towards things; "comfortable," "relaxed," and "natural" scores were significantly increased in 5 studies [20,23, 25, 37, 43], 6 studies [20, $22,23,25,37,43]$, and 6 studies [20, 22, 23, 25, 37, 43], respectively.

\section{Levels of anxiety and depression}

There were 6 studies [30,33, 36, 37, 45, 46] in which levels of anxiety were significantly decreased. There were 3 studies [29, 30, 34] in which levels of depression were significantly decreased.

\section{Degree of physical and psychological recovery}

There were 2 studies [21, 26] involving the degree of physical recovery, in which somatic symptoms were significantly decreased. There were 2 studies [35, 44] in which the degree of psychological recovery and mental health were significantly increased.

\section{Adaptive behavior}

There were 2 studies [29, 34] involving adaptive behavior, and the "self-esteem" score was significantly increased in 1 study [34], and the "health promoting behavior" score was significantly increased in 1 study [29].

\section{Comprehensive study}

The study of the comprehensive health care effect of forest bathing on the human body is still at the primary stage, and the health care mechanism has not been fully proved. It is general practice to assume that forest bathing has positive effects on the physical or psychological health of a certain group of people (such as cardiovascular disease patients, chronic obstructive pulmonary disease patients, the subhealth population, etc.) and to verify whether this hypothesis is valid. The autonomic nervous system that plays a mediating role in the stress response of various systems has attracted the attention of researchers. Based on the data of the 28 papers included in this study, the lnHF of HRV can reflect parasympathetic activity, and the $\operatorname{lnLF} / \mathrm{lnHF}$ of HRV, urinary adrenalin and norepinephrine can reflect sympathetic activity [22, 38]. When participants were exposed to walking in the forest environment, the cerebral cortex was in a relaxed state, parasympathetic activity increased (lnHF increased), and sympathetic activity decreased (lnLF/lnHF, urinary adrenalin and norepinephrine decreased) [20, 25]. Cardiovascular function and hemodynamic index, neuroendocrine index, metabolism index, immune and inflammatory index, antioxidation index, and electrical physiological indexes of the human body, emotional state, attitudes and feelings towards things, physiological and psychological recovery degree, and adaptive behavior of the human body were significantly improved. Levels of anxiety and depression were significantly decreased. Song et al. [24] found that high initial values in parameters such as blood pressure and pulse rate in participants were decreased after walking in the forest environment, while participants with lower initial values had the opposite effect. Participants who walked in urban environments did not experience this 
phenomenon. This indicates that the physiological effect will vary depending on the initial value of the participant, and the forest has a physiological regulation effect close to the appropriate level of the human body, which is not completely caused by the exercise itself. Horiuchi et al. [19] also indicated that the healing effect of forest bathing has nothing to do with the energy expenditure during walking. The health benefits of forest bathing are shown in Fig. 2.

\section{Quality assessment}

For methodological quality assessment of papers based on the Downs and Black checklist, of the 28 papers included in the study, 16 [21, 24, 26, 27, 29-32, 34, 35, 38, $39,41,44-46]$ were of high quality and $12[19,20,22$, $23,25,28,33,36,37,40,42,43]$ were of low quality (Fig. 3). Among the 16 high-quality papers, there were $12[21,24,26,27,30-32,35,38,39,45,46]$ with RCT and $4[29,34,41,44]$ with NRCT. The methodological quality of papers using RCT is significantly higher than that of papers using NRCT $(p<0.05)$ (Fig. 4). On the whole, the quality of papers designed with RCT was higher than those with NRCT. In terms of the generation of random sequences, only 1 paper [30] used computer-generated random codes with a low risk of bias. None of the following was mentioned or carried out in the papers: (1) return visit; (2) blind method for intervention practitioners, participants, or data analysts; (3) explain the compliance with the intervention or control measures; and (4) participants who were lost to follow-up were included in the study or carried out the intention-to-treat analysis.

\section{Discussion}

Studies on the health effects of forest environment exposure on the human body are gradually increasing. Currently, there are two main mainstream models. One is the forest bathing model, which advocates subhealthy people and sick people going into the forest for activities which generate a healing effect through forest environmental factors. Forest bathing can regulate blood pressure, reduce blood glucose, regulate endocrine activity, relieve mental disorders, fight cancer, boost immunity, and treat respiratory diseases [3, 47-52]. In recent years, increasing numbers of forest bathing trial studies have been conducted on people with chronic diseases, such as patients with hypertension or high-normal blood pressure $[22,25,28,30,53]$, chronic obstructive pulmonary disease patients [27], chronic heart failure [32, 39], and chronic stroke [30]. The second is horticultural therapy, which guides sick people into the natural environment and relieves diseases caused mainly by mental stress

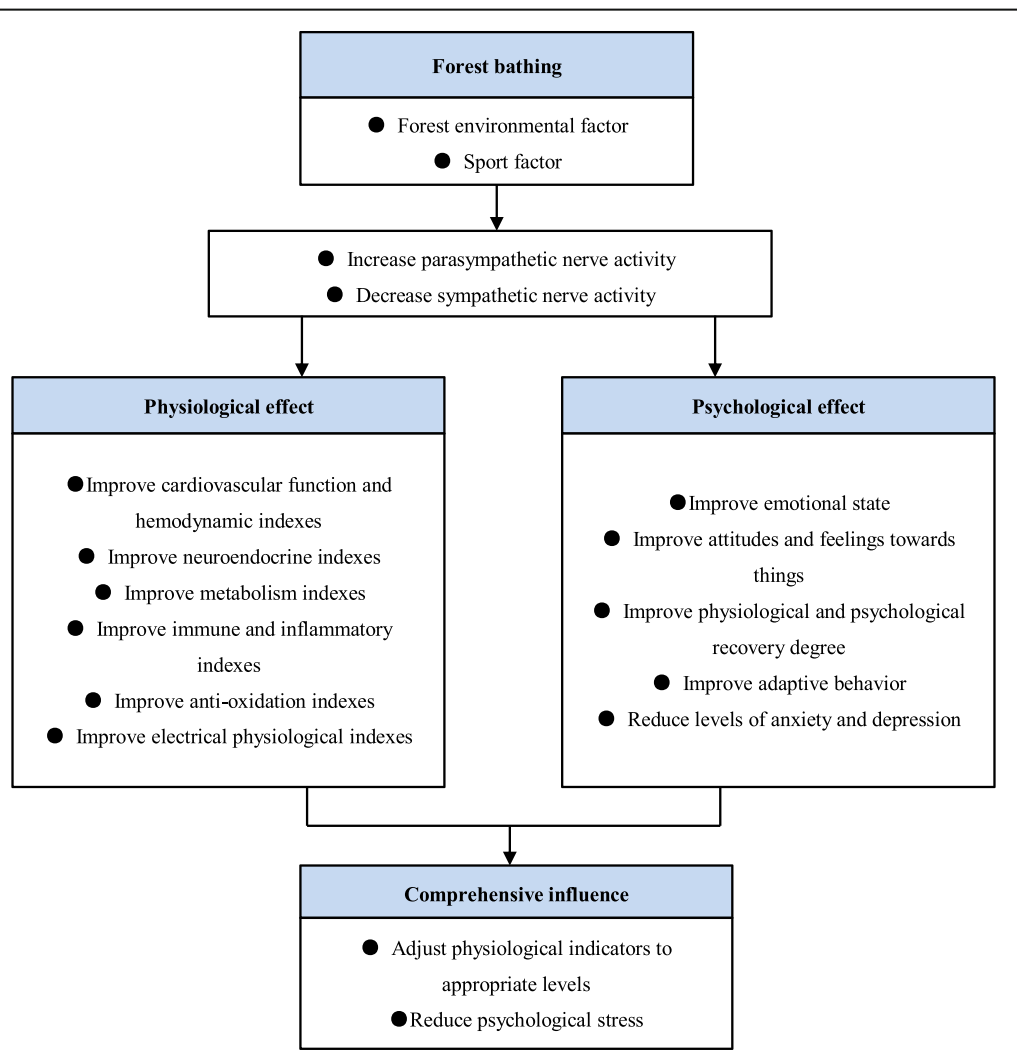

Fig. 2 Health benefits of forest bathing 


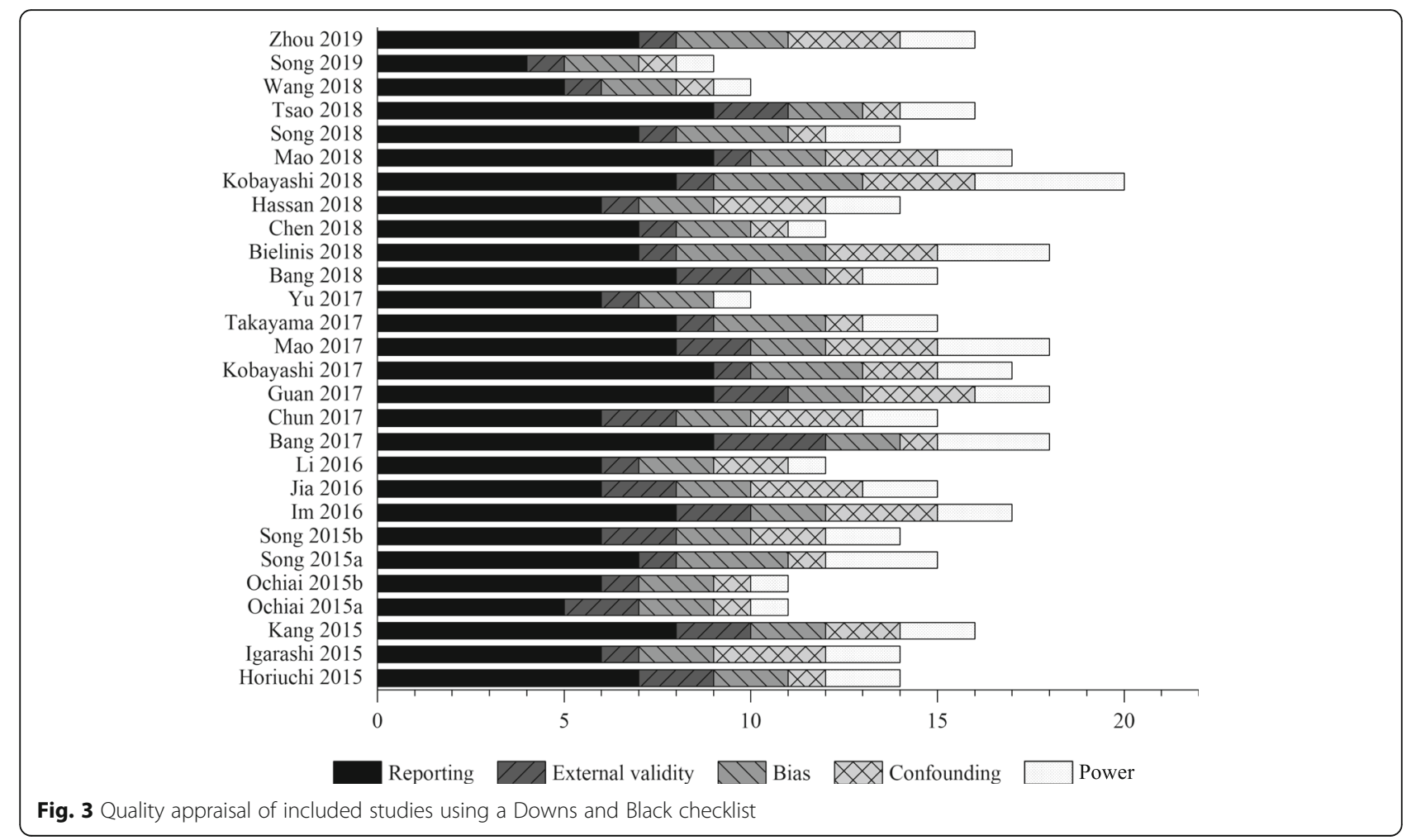

(excessive tension, panic, insomnia, etc.) through communication with people, making crafts, and gardening activities. Others include pain and sports injuries such as mild hemiplegia, lower body paralysis, and cognitive impairments such as speech disorders, spatial identification disorders, memory disorders, attention disorders, and illogicality $[54,55]$. The similarities between forest bathing and horticultural therapy are as follows: (1) They are complementary therapies and cannot replace drugs. (2)

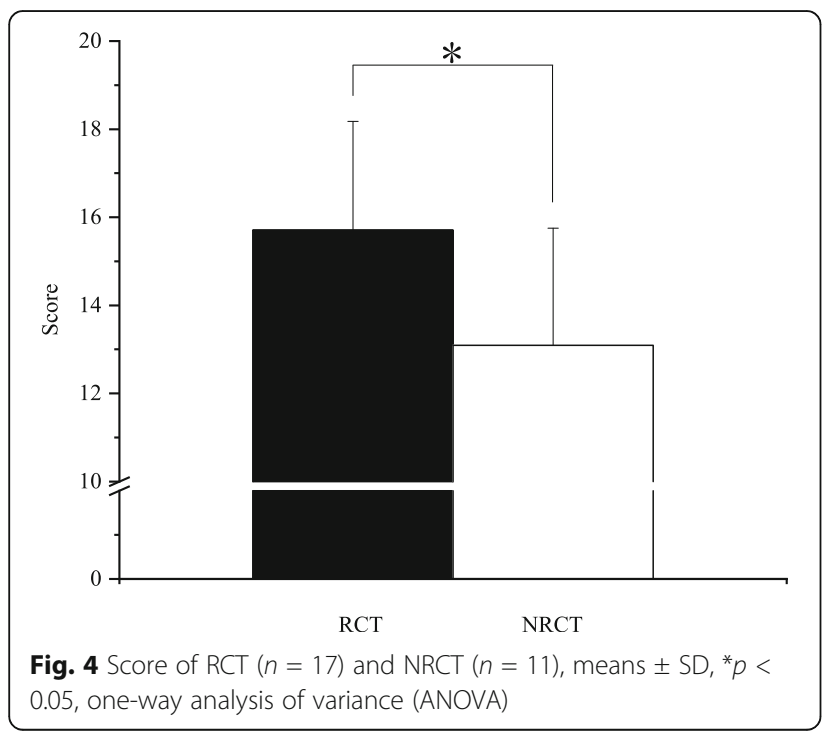

They are a healing method to restore the health of the human body through the "five senses experience." The difference between forest bathing and horticultural therapy are as follows: (1) Their medical categories are different. Forest bathing belongs to the category of preventive medicine, which is mainly aimed at subhealthy people, and the prevention of diseases is its main purpose. Horticultural therapy belongs to the category of rehabilitation medicine, which is mainly aimed at eliminating and reducing dysfunction of the human body, and making up and rebuilding the function of the human body is its main purpose. (2) Their core content is different. The main content of forest bathing is to exercise or meditate in the forest environment, using the forest environmental factors to promote human physical and psychological health. Horticultural therapy is more focused on hand-brain coordination, emphasizing contact with natural things and gaining satisfaction through work. In view of this, different populations should choose appropriate healthcare models. Some scholars [36] combined the 2 healthcare models and achieved very good results.

Based on the data of the 28 papers included in this study, forest bathing has a significant role in promoting human physiology and mental health. Past methods using physiological and self-report measures to distinguish between physiological and psychological research are no longer feasible. The boundaries between the two 
are becoming increasingly blurred. The mainstream research method in the future will be systematic study of physiological measures combined with self-report measures. For example, in the study of the recovery of physical symptoms or the relief of physiological pain, health effects can be shown by physiological indicators, but self-report measures (such as visual analog scale [21], stress response inventory [26], etc.) can also be used for evidence. Research on the regulation of the human emotional state can use self-reported measures for proof, and physiological measures can also be used for evidence (such as HRV [25, 33, 38], brain wave activity [37], and skin electricity [53]). Although the forest environment has obvious effects on the health of the human body and has achieved certain research results, there are still some problems: (1) Lack of basic theoretical research and multidisciplinary communication. At present, most studies are based on qualitative or quantitative analysis of evidence-based medicine, lacking basic theoretical research of forestry. Medical scholars lack guidance from forestry scholars, relying on subjective or instantaneous forest environmental factor data to determine whether a particular forest has health benefits and environmental factors that lead to increased risk of bias. Forest scholars lack guidance from medical scholars, and the trial participants are mostly healthy young people, most of whom fail to consider ethical issues and measure physiological indicators. Some scholars $[45,46]$ conduct small sample studies with homemade scales that fail to pass the reliability and validity test, and the evidence is not convincing enough. (2) The risk of bias in the papers is relatively high. Overall, in the 28 papers included in the study, the random sequence generation, the allocation concealment, and the application of blinded methods are important sources of bias. Loss to follow-up, reported adverse events, and intervention-measures or controlmeasure compliance are the secondary sources of bias. The forest environment is also one of the potential sources of bias.

Interdisciplinary communication between forestry and medicine is an important measure to reduce the bias caused by environmental factors. The forest environment mainly affects human health through "five senses experience," relying on the synergistic effect between a series of forest environmental factors (such as phytoncide, negative air ions, oxygen, and forest microclimate). These environmental factors have significant seasonal, diurnal, and regional variations. The tree species composition and color and forest density are also important influencing factors and can affect human health, especially mental health. Forest environmental factors in individual studies show that phytoncide with antioxidant and antiseptic enhance immunity function [51, 56]. Air negative ions have the effect of increasing parasympathetic activity, relieving depression, and lowering blood glucose [57-59]. The forest microclimate can improve human thermal comfort and reduce heat stress [60, 61]. A large area of green in the forest can bring a sense of security and calm and significantly reduce anxiety and negative emotions [62]. Comprehensive analysis of the forest environment and dynamic monitoring of key environmental factors are important to judge the potential health benefits of the forest and reveal the healthcare mechanism of forest bathing. This has important guiding significance for the formation of industry standards and the establishment of a forest bathing base.

Reducing the risk of bias is an urgent problem to be solved in medical empirical research of forest bathing, for example, RCT, a method of random sequence generation which should be described in detail. The study of low bias risk should use random number tables, computer software for random number generation, flipping a coin, rolling dice, shuffling cards, or envelopes, etc., rather than odd and even numbers, date of birth, subjective assignment, etc. In forest bathing trials, it is complicated to assign concealment and apply a blind method to participants and personnel. If trial conditions are limited, a crossover study can be added to reduce the risk of bias, but the length of the washout period should be considered to avoid a carryover effect. Blind methods should be applied to data collectors and outcome assessors to reduce the risk of bias, as conditions permit. Generally, participants are subjectively more inclined to participate in the forest bathing group than the control group. If the guide introduces too much information about the healthcare efficacy of forest bathing, this may give the participants psychological hints, which may increase the risk of bias. Due to the small number of forest bathing test samples and relatively short trial time, the proportion of participants lost to follow-up is small. In case of followup loss, the risk of bias can be reduced by estimating the missing data and conducting intention-to-treat analysis. Adverse events such as snake bites, pollen allergies, falls, and bruises were rarely mentioned in the forest bathing study. Adverse events during the trial should be explained in the paper. Compliance with intervention or control measures is also rarely mentioned in forest bathing studies, especially for forest bathing activities greater than one day. Participant compliance with intervention measures such as walking, making crafts, meditating, and taking classes, as well as compliance with restrictions or prohibitions on the use of electronic products, communication, caffeine intake, smoking, and drinking, should be explained. 


\section{Conclusion}

Forest bathing activities may significantly improve people's physical and psychological health. In terms of medical empirical studies on forest bathing, the methodological quality of RCTs is significantly higher than that of NRCTs. In the future, medical empirical studies of forest bathing should reinforce basic studies and interdisciplinary exchange to enhance the methodological quality of papers while decreasing the risk of bias, thereby raising the grade of paper evidence.

\section{Appendix}

Table 4 Search words (subject word and random word)

\begin{tabular}{|c|c|c|}
\hline Intervention & Outcome & $\begin{array}{l}\text { Combined } \\
\text { terms }\end{array}$ \\
\hline 1) Forest bathing/ & 17) Health care/ & \multirow{23}{*}{$\begin{array}{ll}37) & 16 \\
\text { AND } 36 & \end{array}$} \\
\hline $\begin{array}{l}\text { 2) Forest nature } \\
\text { convalescent/ }\end{array}$ & 18) Healing/ & \\
\hline 3) Forest therapy/ & 19) Therapy/ & \\
\hline 4) Shinrin-yoku/ & 20) Recover/ & \\
\hline 5) Forest travel/ & 21) Vigor/ & \\
\hline 6) Forest walking/ & 22) Spirit/ & \\
\hline 7) Forest yoga/ & 23) Pressure/ & \\
\hline 8) Forest/ & 24) Depression/ & \\
\hline 9) Forest meditation/ & 25) Anxiety/ & \\
\hline 10) Forest environment/ & 26) Brain wave/ & \\
\hline 11) Forest areas/ & 27) Pulse/ & \\
\hline 12) Phytoncide/ & 28) Heart rate/ & \\
\hline 13) Negative air ions/ & 29) Blood pressure/ & \\
\hline 14) Negative oxygen ions/ & 30) Blood glucose/ & \\
\hline 15) Oxygen/ & 31) Saliva/ & \\
\hline \multirow{8}{*}{$\begin{array}{c}\text { 16) } 1 \text { OR } 2 \text { OR } 3 \text { OR } 4 \text { OR } 5 \\
\text { OR } 6 \text { OR } 7 \text { OR } 8 \text { OR } 9 \text { OR } 10 \\
\text { OR } 11 \text { OR } 12 \text { OR } 13 \text { OR } 14 \\
\text { OR } 15\end{array}$} & 32) Inflammatory factor/ & \\
\hline & 33) Immune/ & \\
\hline & 34) Hormonal readiness/ & \\
\hline & 35) Skin conductance/ & \\
\hline & 36) 17 OR 18 OR 19 OR 20 & \\
\hline & OR 21 OR 22 OR 23 OR 24 & \\
\hline & OR 25 OR 26 OR 27 OR 28 & \\
\hline & $\begin{array}{c}\text { OR } 29 \text { OR } 30 \text { OR } 31 \text { OR } 32 \\
\text { OR } 33 \text { OR } 34 \text { OR } 35\end{array}$ & \\
\hline
\end{tabular}

\section{Abbreviations}

HRV: Heart rate variability; IL: Interleukin; InHF: The natural logarithmic value of the high frequency of heart rate variability; InLF: The natural logarithmic value of the low frequency of heart rate variability; NK: Nature killer; NRCT: Non-randomized controlled trial; RCT: Randomized controlled trial; SBP: Systolic blood pressure

\section{Acknowledgements}

Not applicable

\section{Authors' contributions}

$Y L$ and $X G$ conceived this study. YW analyzed the data and was a major contributor in writing the manuscript. YW, QY, and YP conducted the systematic review. All authors read and approved the final manuscript.

\section{Funding}

This work was supported by funds from the National Natural Science Foundation of China (31660230)

Availability of data and materials

Not applicable

Ethics approval and consent to participate

Not applicable

Consent for publication

Not applicable

\section{Competing interests}

The authors declare that they have no competing interests.

\section{Author details}

${ }^{1}$ College of Forestry, Jiangxi Agricultural University, 1101 ZhiMin Road, Nanchang 330045, China. 'Jiangxi Academy of Forestry, 1629 FengLin Road, Nanchang 330032, China.

Received: 22 July 2019 Accepted: 1 October 2019

Published online: 01 December 2019

\section{References}

1. Xie YM, Liu BY, Piao HY. Exploration on the common characters of subhealthy people based on clinical epidemiology. Chin J Integr Med. 2006; 26(7):612-6.

2. Zhao H, Xiong WH, Zhao X, Wang LM, Chen JX. Development and evaluation of a traditional chinese medicine syndrome questionnaire for measuring sub-optimal health status in China. J Tradit Chin Med. 2012;32(2): 129-36.

3. Tsunetsugu Y, Park BJ, Miyazaki Y. Trends in research related to "Shinrinyoku"(taking in the forest atmosphere or forest bathing) in Japan. Environ Health Prev Med. 2010;15(1):27.

4. Kessler RC, Berglund PA, Coulouvrat C, Hajak G, Roth T, Shahly V, et al. Insomnia and the performance of US workers: results from the America insomnia survey. Sleep. 2011;34(9):1161-71.

5. Walsh JK, Coulouvrat C, Hajak G, Lakoma MD, Petukhova M, Roth T, et al. Nighttime insomnia symptoms and perceived health in the America Insomnia Survey (AIS). Sleep. 2011;34(8):997-1011.

6. Fayaz A, Croft P, Langford RM, Donaldson LJ, Jones GT. Prevalence of chronic pain in the UK: a systematic review and meta-analysis of population studies. BMJ open. 2016;6(6):e010364.

7. Bowler DE, Buyung-Ali LM, Knight TM, Pullin AS. A systematic review of evidence for the added benefits to health of exposure to natural environments. BMC Public Health. 2010;10(1):456.

8. Li Q. Effect of forest bathing trips on human immune function. Environ Health Prev Med. 2010;15(1):9.

9. Oh B, Lee KJ, Zaslawski C, Yeung A, Rosenthal D, Larkey L, et al. Health and well-being benefits of spending time in forests: systematic review. Environ Health Prev Med. 2017;22(1):71.

10. Twohig-Bennett $C$, Jones $A$. The health benefits of the great outdoors: a systematic review and meta-analysis of greenspace exposure and health outcomes. Environ Res. 2018;166:628-37.

11. Song C, Ikei H, Miyazaki Y. Physiological effects of nature therapy: a review of the research in Japan. Int J Environ Res Public Health. 2016;13(8):781.

12. Lee I, Choi H, Bang KS, Kim S, Song M, Lee B. Effects of forest therapy on depressive symptoms among adults: a systematic review. Int J Environ Res Public Health. 2017:14(3):321.

13. Hansen MM, Jones R, Tocchini K. Shinrin-yoku (forest bathing) and nature therapy: a state-of-the-art review. Int J Environ Res Public Health. 2017;14(8):851. 
14. Furuyashiki A, Tabuchi K, Norikoshi K, Kobayashi T, Oriyama S. A comparative study of the physiological and psychological effects of forest bathing (Shinrin-yoku) on working age people with and without depressive tendencies. Environ Health Prev Med. 2019;24(1):46.

15. Mao GX, Lan XG, Cao YB, Chen ZM, He ZH, Lv YD, et al. Effects of short-term forest bathing on human health in a broad-leaved evergreen forest in Zhejiang Province. China. Biomed Environ Sci. 2012;25(3):317-24.

16. Shin YK, Kim DJ, Jung-Choi K, Son YJ, Koo JW, Min JA, et al. Differences of psychological effects between meditative and athletic walking in a forest and gymnasium. Scand J Forest Res. 2013;28(1):64-72.

17. Downs SH, Black N. The feasibility of creating a checklist for the assessment of the methodological quality both of randomised and non-randomised studies of health care interventions. J Epidemiol Community Health. 1998; 52(6):377-84.

18. Moher D, Shamseer $L$, Clarke M, Ghersi D, Liberati A, Petticrew M, et al. Preferred reporting items for systematic review and meta-analysis protocols (PRISMA-P) 2015 statement. Systematic Reviews. 2015;4(1):1.

19. Horiuchi M, Endo J, Akatsuka S, Hasegawa T, Yamamoto E, Uno T, et al. An effective strategy to reduce blood pressure after forest walking in middleaged and aged people. J Phys Ther Sci. 2015;27(12):3711-6.

20. Igarashi M, Miwa M, Ikei H, Song C, Takagaki M, Miyazaki Y. Physiological and psychological effects of viewing a kiwifruit (Actinidia deliciosa 'hayward') orchard landscape in summer in Japan. Int J Environ Res Public Health. 2015;12(6):6657-68.

21. Kang B, Kim T, Kim MJ, Lee KH, Choi S, Lee DH, et al. Relief of chronic posterior neck pain depending on the type of forest therapy: comparison of the therapeutic effect of forest bathing alone versus forest bathing with exercise. Ann Rehabil Med. 2015;39(6):957-63.

22. Ochiai H, Ikei H, Song C, Kobayashi M, Takamatsu A, Miura T, et al. Physiological and psychological effects of forest therapy on middle-aged males with high-normal blood pressure. Int J Environ Res Public Health. 2015a;12(3):2532-42.

23. Ochiai H, Ikei H, Song C, Kobayashi M, Miura T, Kagawa $T$, Li Q, et al. Physiological and psychological effects of a forest therapy program on middle-aged females. Int J Environ Res Public Health. 2015b;12(12): 15222-32.

24. Song C, Ikei H, Miyazaki Y. Elucidation of a physiological adjustment effect in a forest environment: A pilot study. Int J Environ Res Public Health. 2015a;12(4):4247-55.

25. Song C, Ikei H, Kobayashi M, Miura T, Taue M, Kagawa T, et al. Effect of forest walking on autonomic nervous system activity in middle-aged hypertensive individuals: A pilot study. Int J Environ Res Public Health. 2015b;12(3):2687-99.

26. Im S, Choi H, Jeon YH, Song MK, Kim W, Woo JM. Comparison of effect of two-hour exposure to forest and urban environments on cytokine, antioxidant, and stress levels in young adults. Int J Environ Res Public Health. 2016;13(7):625

27. Jia BB, Yang ZX, Mao GX, Lyu YD, Wen XL, Xu WH, et al. Health effect of forest bathing trip on elderly patients with chronic obstructive pulmonary disease. Biomed Environ Sci. 2016;29(3):212-8.

28. Li Q, Kobayashi M, Kumeda S, Ochiai T, Miura T, Kagawa T, et al. Effects of forest bathing on cardiovascular and metabolic parameters in middle-aged males. Evid-Based Compl Alt. 2016;2016:1-7.

29. Bang KS, Lee I, Kim S, Lim CS, Joh HK, Park BJ, et al. The effects of a campus forest-walking program on undergraduate and graduate students' physical and psychological health. Int J Environ Res Public Health. 2017;14(7):728.

30. Chun MH, Chang MC, Lee SJ. The effects of forest therapy on depression and anxiety in patients with chronic stroke. Int J Neurosci. 2017;127(3):199-203.

31. Kobayashi H, Song C, Ikei H, Park BJ, Lee J, Kagawa T, et al. Populationbased study on the effect of a forest environment on salivary cortisol concentration. Int J Environ Res Public Health. 2017;14(8):931.

32. Mao G, Cao Y, Wang B, Wang S, Chen Z, Wang J, et al. The salutary influence of forest bathing on elderly patients with chronic heart failure. Int J Environ Res Public Health. 2017;14(4):368.

33. Yu CP, Lin CM, Tsai MJ, Tsai Y, Chen C. Effects of short forest bathing program on autonomic nervous system activity and mood states in middleaged and elderly individuals. Int J Environ Res Public Health. 2017;14(8):897.

34. Bang KS, Kim S, Song M, Kang Kl, Jeong Y. The effects of a health promotion program using urban forests and nursing student mentors on the perceived and psychological health of elementary school children in vulnerable populations. Int J Environ Res Public Health. 2018;15(9):1977.
35. Bielinis E, Takayama N, Boiko S, Omelan A, Bielinis L. The effect of winter forest bathing on psychological relaxation of young Polish adults. Urban For Urban Gree. 2018;29:276-83.

36. Chen HT, Yu CP, Lee HY. The effects of forest bathing on stress recovery: evidence from middle-aged females of taiwan. Forests. 2018;9(7):403.

37. Hassan A, Tao J, Li G, Jiang M, Liu A, Jiang Z, et al. Effects of walking in bamboo forest and city environments on brainwave activity in young adults. Evid-Based Compl Alt. 2018;2018:1-9.

38. Kobayashi H, Song C, Ikei H, Park BJ, Lee J, Kagawa T, et al. Forest walking affects autonomic nervous activity: a population-based study. Front. Public Health. 2018:6:278.

39. Mao GX, Cao YB, Yan Y, Chen ZM, Dong JH, Chen SS, et al. Additive benefits of twice forest bathing trips in elderly patients with chronic heart failure. Biomed Environ Sci. 2018;31(2):159-62.

40. Song C, Ikei H, Park BJ, Lee J, Kagawa T, Miyazaki Y. Psychological benefits of walking through forest areas. Int J Environ Res Public Health. 2018;15(12):2804.

41. Tsao TM, Tsai MJ, Hwang JS, Cheng WF, Wu CF, Chou CK, et al. Health effects of a forest environment on natural killer cells in humans: an observational pilot study. Oncotarget. 2018;9(23):16501-11.

42. Wang DH, Yamada A, Miyanaga M. Changes in urinary hydrogen peroxide and 8-hydroxy-2'-deoxyguanosine levels after a forest walk: a pilot study. Int J Environ Res Public Health. 2018;15(9):1871.

43. Song C, Ikei H, Kagawa T, Miyazaki Y. Effects of walking in a forest on young women. Int J Environ Res Public Health. 2019;16(2):229.

44. Takayama N, Fujiwara A, Saito H, Horiuchi M. Management effectiveness of a secondary coniferous forest for landscape appreciation and psychological restoration. Int J Environ Res Public Health. 2017;14(7):800.

45. Guan H, Wei H, He X, Ren Z, An B. The tree-species-specific effect of forest bathing on perceived anxiety alleviation of young-adults in urban forests. Ann For Res. 2017;60(2):327-41.

46. Zhou C, Yan L, Yu L, Wei H, Guan H, Shang C, et al. Effect of short-term forest bathing in urban parks on perceived anxiety of young-adults: a pilot study in Guiyang, southwest China. Chinese Geogr Sci. 2019;29(1):139-50.

47. Li Q, Nakadai A, Matsushima H, Miyazaki Y, Krensky AM, Kawada T, et al. Phytoncides (wood essential oils) induce human natural killer cell activity. Immunopharm Immunot. 2006;28(2):319-33.

48. Li Q, Morimoto K, Nakadai A, Inagaki H, Katsumata M, Shimizu T, et al. Forest bathing enhances human natural killer activity and expression of anticancer proteins. Int J Immunopath Ph. 2007;20(suppl 2):3-8.

49. Li Q, Morimoto K, Kobayashi M, Inagaki H, Katsumata M, Hirata Y, et al. A forest bathing trip increases human natural killer activity and expression of anti-cancer proteins in female subjects. Int J Environ Res Public Health. 2008;22(1):45-55.

50. Li Q, Morimoto K, Kobayashi M, Inagaki H, Katsumata M, Hirata Y, et al. Visiting a forest, but not a city, increases human natural killer activity and expression of anti-cancer proteins. Int J Immunopath Ph. 2008;21(1):117-27.

51. Li Q, Kobayashi M, Wakayama Y, Inagaki H, Katsumata M, Hirata $Y$, et al. Effect of phytoncide from trees on human natural killer cell function. Int J Immunopath Pharmacol. 2009;22(4):951-9.

52. Zheng Q, Yang X. Study and practice of forest-bathing field in Japan. Asian Agr Res. 2013;5(2):18.

53. Mao GX, Cao YB, Lan XG, He ZH, Chen ZM, Wang YZ, et al. Therapeutic effect of forest bathing on human hypertension in the elderly. J Cardiol. 2012;60(6):495-502.

54. Fletcher L, Hayes SC. Relational frame theory, acceptance and commitment therapy, and a functional analytic definition of mindfulness. J Ration-Emot Cogn -B. 2005;23(4):315-36.

55. Corazon SS, Stigsdotter UK, Jensen AGC, Nilsson K. Development of the nature-based therapy concept for patients with stress-related illness at the Danish healing forest garden Nacadia. J Ther Hortic. 2010;20:30-48.

56. Abe T, Hisama M, Tanimoto S, Shibayama H, Mihara Y, Nomura M. Antioxidant effects and antimicrobial activites of phytoncide. Biocontrol Sci. 2008;13(1):23-7.

57. Goel N, Terman M, Terman JS, Macchi MM, Stewart JW. Controlled trial of bright light and negative air ions for chronic depression. Psychol Med. 2005; 35(7):945-55.

58. Bowers B, Flory R, Ametepe J, Staley L, Patrick A, Carrington H. Controlled trial evaluation of exposure duration to negative air ions for the treatment of seasonal affective disorder. Psychiatry Res. 2018;259:7-14.

59. Ohtsuka Y, Yabunaka N, Takayama S. Shinrin-yoku (forest-air bathing and walking) effectively decreases blood glucose levels in diabetic patients. Int J Biometeorol. 1998;41(3):125-7. 
60. De Abreu-Harbich LV, Labaki LC, Matzarakis A. Effect of tree planting design and tree species on human thermal comfort in the tropics. Landscape Urban Plan. 2015;138:99-109.

61. Kong L, Lau KKL, Yuan C, Chen Y, Xu Y, Ren C, et al. Regulation of outdoor thermal comfort by trees in Hong Kong. Sustain Cities and Soc. 2017;31:12-25.

62. Akers A, Barton J, Cossey R, Gainsford P, Griffin M, Micklewright D. Visual color perception in green exercise: Positive effects on mood and perceived exertion. Environ sci technol. 2012;46(16):8661-6.

\section{Publisher's Note}

Springer Nature remains neutral with regard to jurisdictional claims in published maps and institutional affiliations.

Ready to submit your research? Choose BMC and benefit from:

- fast, convenient online submission

- thorough peer review by experienced researchers in your field

- rapid publication on acceptance

- support for research data, including large and complex data types

- gold Open Access which fosters wider collaboration and increased citations

- maximum visibility for your research: over $100 \mathrm{M}$ website views per year

At BMC, research is always in progress.

Learn more biomedcentral.com/submissions 